\title{
Hybrid capacitive deionization with anion- exchange membranes for lithium extraction
}

\author{
Anna Siekierka ${ }^{1, *}$, Marek Bryjak $^{1}$ \\ ${ }^{1}$ Wroclaw University of Science and Technology, Faculty of Chemistry, Wyb.Wyspiańskiego 27, \\ Wroclaw, Poland
}

\begin{abstract}
Lithium is considered to be a critical material for various industrial fields. We present our studies on extraction lithium from diluted aqueous solution by novel hybrid system based on a membrane capacitive deionization and batteries desalination. Hybrid CDI is comprised by a lithium selective adsorbent, activated carbon electrode and anion-exchange membranes. Here, we demonstrated implication of various type of anionexchange membranes and influence their properties on effective capacity and energy requirements in charge/discharge steps. We described a configuration with anion-exchange membrane characterized by adsorption capacity of $35 \mathrm{mg} / \mathrm{g}$ of $\mathrm{Li}^{+}$with $0.08 \mathrm{Wh} / \mathrm{g}$ and removal efficiency of $60 \%$ of lithium ions, using novel selective desalination technique.
\end{abstract}

\section{Introduction}

The global market for lithium salts is a fast growing and is expected to reach $30 \$$ billion value by 2020. Increasing rapidly demand of $\mathrm{Li}$ ions is caused by their application for portable electronics, for electric and hybrid cars and for electrical intelligent grids [1]. Information on individual lithium resources has been collected and divided into two main categories: extraction from natural as minerals, salt lakes, underground brines or seawater, and the recycling of lithium from electronic waste and lithium ions batteries [2]. However, the most promising lithium ions depositions are estimated at groundwater's and brines where its content is evaluated to be $2.55 \cdot 10^{14} \mathrm{~kg}$ [3].

Seawater desalination process require electric or thermal technology to separate saline water into two streams, fresh water with a low concentration of dissolved salts and a concentrated brine stream. A variety desalination technology have been developed over year. Reverse osmosis and multistage flash distillation require a large electrical energy input which accounts for an approximately $50 \%$ of its costs [4]. Forward osmosis is a promising method that utilizes lower temperatures $\left(60^{\circ} \mathrm{C}\right)$ than MFD but still requires energy. A search for less energy consuming technique was finalized with launching capacitive deionization based on the use of supercapacitors [7]. Finally, a new concept of a "desalination battery" which has configuration similar to CDI, but with different electrode materials, was investigated. In this case, system is consist of cationic sodium insertion electrode and a chloride-capturing anionic electrode, made of Ag [4]. Batteries electrode

\footnotetext{
*Corresponding author: anna.siekierka@pwr.edu.pl
} 
pose higher specific capacity and lower energy requirement than capacitive deionization [4].

In this paper, we were investigated a novel combination of membrane capacitive deionization and battery desalination, called hybrid capacitive deionization or ion-pumping process with electrical potential assembly. The goal of the paper is to develop a search for lithium selective system suitable for construction of electrodes and for extraction of lithium ions with higher efficiency. Preliminary application of CDI to extraction lithium from diluted aqueous solutions was confirmed in our previously paper[6]. In this investigation, we evaluated a system built with lithium selective adsorbent as a anode, activated carbonaceous electrode for chloride ions capturing coated with anion-exchange membrane that prevented adsorption released lithium on the surface of counter electrode (co-ions effect [7]). We compare systems with our PVC-aminated anion-exchange membrane with industrial AMX-408 to find the best combination with the highest capacity and lowest energy requirements for selective lithium extraction.

\section{Materials and Methods}

\subsection{Electrodes}

\subsubsection{Activated Carbon}

YP-50F Kuraray Chemical Co. LTD. Osaka, Japan, steam activated coconut carbon (AC) was used throughout this study. Its characteristic can be found in Tab.1.

\subsubsection{Lithium adsorbent}

Spinel lithium-manganese-titanium oxide (LMTO) with $5 \%$ wt. of Ti was prepared according to procedure described in ref. [5]. Its characteristic can be found in Tab.1.

Table 1. Specific surface area and pore volume of LMTO and AC

\begin{tabular}{ccccc}
\hline Sample & $\begin{array}{c}\text { Specific surface } \\
\text { area SBET }\left(\mathbf{m}^{\mathbf{2}} \mathbf{g}^{-1}\right)\end{array}$ & $\begin{array}{c}\text { Pore volume } \\
\left(\mathbf{c m}^{\mathbf{3}} \mathbf{g}^{-1}\right)\end{array}$ & $\begin{array}{c}\text { Pore diameter } \\
(\mathbf{n m})\end{array}$ & Ref. \\
\hline LMTO & 54.9 & 0.113 & 1.03 & {$[5]$} \\
\hline AC & 1672 & 0.757 & 1.65 & {$[5]$} \\
\hline
\end{tabular}

\subsubsection{Preparation of electrode}

Both electrodes were prepared by mixing $90 \% \mathrm{wt}$. of lithium adsorbent or activated carbon, with $10 \%$ wt. of PVC dissolved in DMF (3.5\% wt. solution of polymer). Paste was stirred by ultrasonication supply for 30 minutes at room temperature. Finally, slurry was cast on the graphite foil and electrode of $70-80 \mu \mathrm{m}$ was formed by casting knife. The evaporation of solvent was carried out by $2 \mathrm{~h}$ in vacuum dryer. The prepared electrodes were kept in DI water. Before measurement electrode were been activated 3 times in charge-discharge process to remove any contaminants from electrodes.

\subsection{Anion-exchange membranes}

Amine modified poly(vinyl chloride) membranes were used in the experiments. Selected membranes were obtained by chemical modification of poly(vinyl chloride) by ethylene diamine (EDA) or diethylene tetra-amine (DETA). Details of modification and preparation 
can found in ref. [8]. Fundamental properties of PVC-amines membranes are presented at Tab. 2

Table 2. Properties of PVC-EDA and PVC-DETA

\begin{tabular}{|c|c|c|c|c|c|c|c|}
\hline Sample & $\begin{array}{c}{ }^{1} \mathbf{Z}_{\text {IEC }} \\
{[\mathrm{mmole} / \mathrm{g}]}\end{array}$ & $\begin{array}{c}{ }^{2} \mathrm{Z}_{\mathrm{Cl}} \\
{[\mathrm{mmole} / \mathrm{g}]}\end{array}$ & $\begin{array}{c}{ }^{3} Z_{N} \\
{[\mathrm{mmole} / \mathrm{g}]}\end{array}$ & $\begin{array}{c}{ }^{4} W_{H 2 O} \\
{[g / g]}\end{array}$ & $\begin{array}{l}{ }^{5} \mathrm{MD} \\
{[\%]}\end{array}$ & $\begin{array}{c}{ }^{6} \mathbf{P} \\
{[\%]}\end{array}$ & Ref. \\
\hline PVC-EDA & 3.5 & 11.8 & 3.3 & 0.4 & 23.9 & 17.5 & [3] \\
\hline PVC-DETA & 2.6 & 12.0 & 3.0 & 0.9 & 22.6 & 17.8 & [3] \\
\hline
\end{tabular}

${ }^{I}$ Ion-exchange capacity was estimated according to acid-base method

${ }^{2}$ Chloride content was determined according Schöniger's method

${ }^{3}$ Nitrogen content was determined by Kjeldahl's method

${ }^{4}$ Water uptake

${ }^{5}$ Modification degree was calculated as the relative content of chloride

${ }^{6}$ Polarity was taken as a partition of polar component to total surface energy

Before measurements membranes were kept in ethanol:water solution $(40: 60 \mathrm{v}: \mathrm{v})$ to activated functional groups. After $24 \mathrm{~h}$ were washed by DI water. To compare anionexchange properties of obtained membranes, Neosepta AMX-408 membrane was used. Its characteristic can be found on the manufacturer web page [9].

\subsection{Layout of hybrid CDI system}

\subsubsection{Hybrid CDI system configuration}

To study desalination performance of chloride salts, a laboratory electrodialyzer FT-ED100-4 was used. The stack composed of two electrode and anion-exchange membrane while electrodes were divided by spacer of $200 \mu \mathrm{m}$ thickness. As a anode (negatively polarized) spinel lithium-manganese-titanium oxide (LMTO) with $5 \%$ wt. of Ti was mounted [6]. As cathode activated carbon YP-50F was used. LMTO electrode was used for selective capturing $\mathrm{Li}^{+}$ions and a $\mathrm{AC}$ electrode was used to capture $\mathrm{Cl}^{-}$ions. To prevent the effect of co-ions adsorption [7] in desorption step of the hybrid CDI testing, anionexchange membrane was applied on AC electrode.

Desalination performance was evaluated under constant voltage mode (CV). The electrodialyzer was biased by DC power from Konrad KD3005D Digital-Control DC Power Supply with 2V. The fluid properties were monitored with U3401A Digit Dual Display Multimeter and with CPC-501 meter. To investigate selectivity of lithium adsorbent, solutions of $\mathrm{LiCl}, \mathrm{NaCl}$ and $\mathrm{KCl}$, of $10 \mathrm{mM}$ concentration were used. The adsorption and desorption steps were carried out for $10 \mathrm{~min}$ at $25^{\circ} \mathrm{C}$.

\subsubsection{Calculations section}

In all experiments, such metrics as salt adsorption capacity (SAC) and average salt adsorption rate (ASAR) were calculated:

$$
\begin{gathered}
S A C(\mathrm{mg} / \mathrm{g})=\left[\left(C_{0}-C_{f}\right) \cdot \mathrm{V}\right] / \mathrm{m} \\
A S A R(\mathrm{mg} / \mathrm{g} \cdot \mathrm{s})=S A C / \mathrm{t}_{\text {charge }}
\end{gathered}
$$

where, $C_{o}\left(\mathrm{mg} / \mathrm{dm}^{3}\right)$ and $C_{f}\left(\mathrm{mg} / \mathrm{dm}^{3}\right)$ are initial and final salt concentration, $V\left(\mathrm{dm}^{3}\right)$ is the solution volume, and $\mathrm{m}(\mathrm{g})$ is the mass of both electrodes, $\mathrm{t}_{\text {charge }}(\mathrm{s})$ is charging time.

The important parameter for evaluation of the stack working in the $\mathrm{CV}$ mode, is charge efficiency $\Lambda$ that is given by: 


$$
\Lambda=\left[\left(C_{0}-C_{f}\right) \cdot \mathrm{V} \cdot \mathrm{F}\right] / Q
$$

where $\mathrm{F}$ is the Faraday's number, $\mathrm{F}=96485\left(\mathrm{C} \cdot \mathrm{mol}^{-1}\right), \mathrm{Q}$ is a charge stored for charging steps and was calculated by integration of the current and time of charging.

To analyze energy consumption and calculate system capacity, the simple RC circuit with measurement of current change was used. Total energy consumption ( $\left.\mathrm{E}_{\text {total }}\right)$ was the sum of energy for adsorption $\left(\mathrm{E}_{\mathrm{ads}}\right)$ and for desorption $\left(\mathrm{E}_{\mathrm{des}}\right)$ processes, and were computed from numerical integration of current versus time relationship $[10,11]$. Next metrics is energy normalized adsorbed salt (ENAS) in units of grams per Joules of energy total and is defined as

$$
E N A S=\left[\int\left(C_{0}-C_{f}\right) \mathrm{d} t\right] / E_{\text {total }}
$$

Which quantifies the energetic efficiency of the desalination process. Last metrics described hybrid capacitive deionization process is electrical work in Wh per gram of salt and is defined as

$$
W=Q \cdot \mathrm{V} /\left[\int\left(C_{0^{-}} C_{f}\right) \mathrm{d} t\right]
$$

It expresses consumed energy that has use the system to adsorb or desorb one gram of salt. $\mathrm{Q}$ is a charge flow by system during adsorption/desorption process and $\mathrm{V}$ is electrical potential between electrodes.

\subsubsection{Analytical section}

Membranes were analysed using a scanning electron microscope (SEM, Tescan Vega3 SB). All samples were gold-coated for $60 \mathrm{~s}$ and $7 \mathrm{~nm}$ thickness before SEM imaging to reduce the effect of charging.

\section{Results and Discussion}

\subsection{SEM morphology examination}

The surface structure of anion-exchange membranes were determined by using SEM images. In Fig.1 one sees SEM images surface of PVC-DETA and PVC-EDA membranes.

It can be noted the morphology change happened during amination step. It is possible that new functional group were introduced which added some kind of aggregates on the surface and increased their roughness. When comparing the SEM images, the PVC-DETA was characterized by more homogenous diameter of aggregates than the second membrane. The average value was located in the range $28-35 \mathrm{~nm}$.
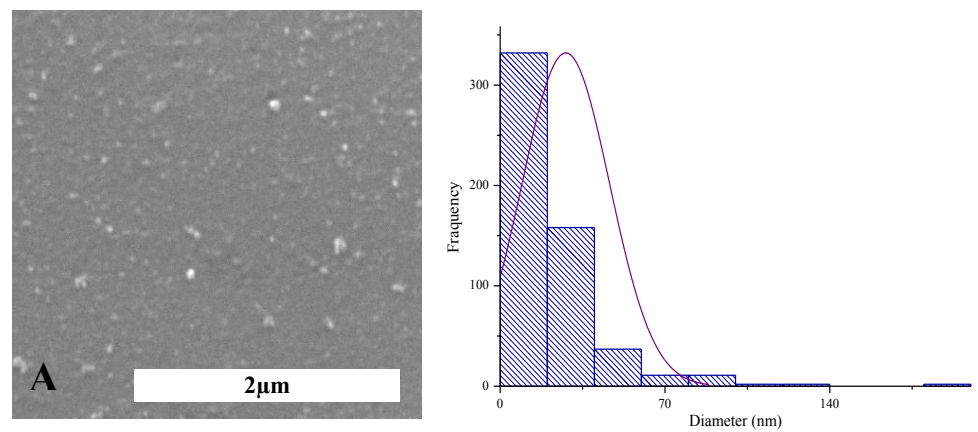

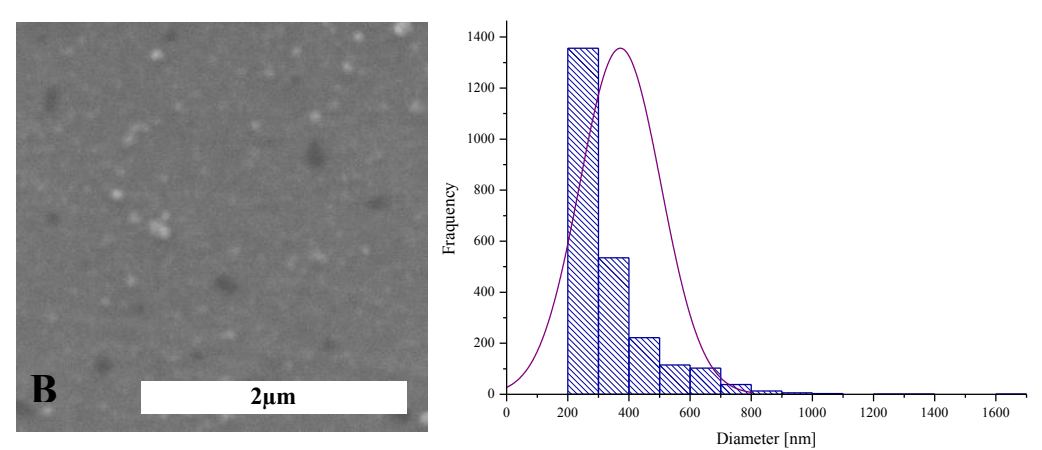

Fig.1. SEM images and aggregate size distribution for (A) PVC-DETA and (B) PVC-EDA.

\subsection{Hybrid Capacitive Deionization}

To presented the most prominent aspects of the hybrid CDI system the CDI Ragone plot was used. To see implications of the CDI Ragone plot, we compared different anionexchange membranes at the same system parameters. Additionally, we evaluated the plot for desorption process.

All collected data are showed ideal capacitive deionization performances, according to reference [12]. When compared the results for configuration with and without anionexchange membranes and noted higher capacity and rate value for system equipped with membrane. Application of anion-exchange membranes provided shift of the plot up (Fig.2A) and caused an opportunity to gain salt adsorption capacity at $45 \mathrm{mg} / \mathrm{g}$ for PVCEDA and for AMX-408 membranes in 10 minutes. At Fig.2B one can observe different behaviour. The stack with PVC-DETA membrane approached zero and thereby released adsorbed lithium to concentrated solution.
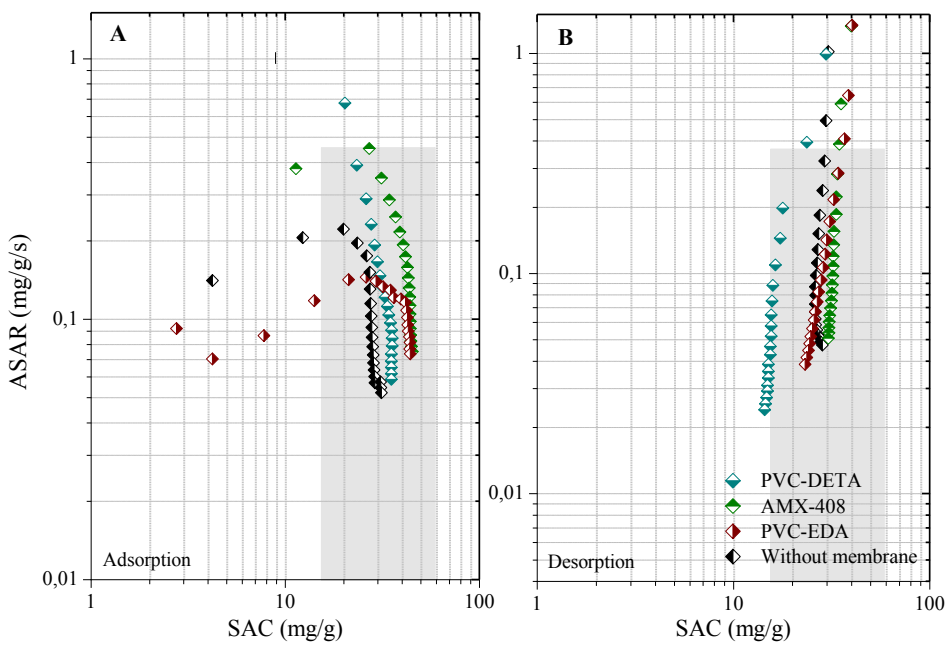

Fig.2. Effect of used different membranes in hybrid CDI in (A) adsorption and (B) desorption processes. The grey region marked at the plot is related with ideal performance described at [12].

Effect of desorption against concentration gradient is also seen in Fig.3. This graph shows removal efficiency of lithium chloride and repeatability of salt extraction. Based on these results it can be deduced that system with anion-exchange membrane directly influenced on 
removal efficiency of lithium chloride during desorption process. Moreover, it can be noted that layout of hybrid CDI system with PVC-DETA exhibited the higher of $60 \%$ removal efficiency allowed to obtain two times higher capacity than configuration with industrial membrane AMX-408. It was also six times more efficient than system without membrane.

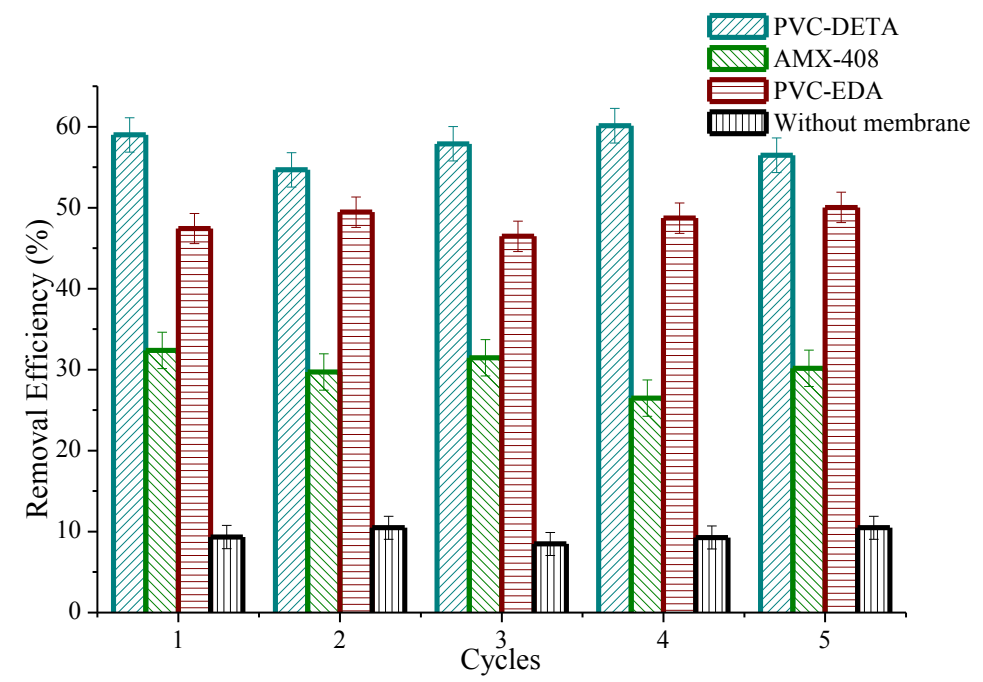

Fig.3. Removal Efficiency of $\mathrm{LiCl}$ for system. Time of removal $10 \mathrm{~min}$. Used voltage $2 \mathrm{~V}$. Three times of repeatability.

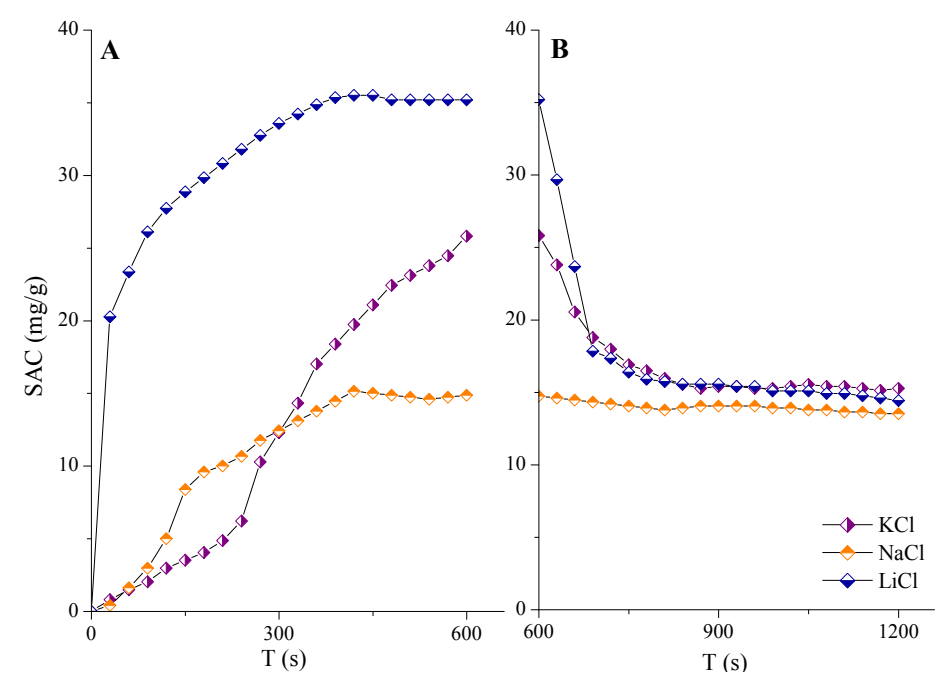

Fig.4. Changed $\mathrm{NaCl}, \mathrm{KCl}$ and $\mathrm{LiCl}$ salt adsorption capacity during (A) adsorption and (B) desorption for configuration with PVC-DETA membrane. 10 minute of charge and disachrge steps, bias $2 \mathrm{~V}$.

The most critical parameter fo selective extraction of lithium is its comparision to other monovalents salts. In this case $10 \mathrm{mM}$ of sodium and potassium chlorides were emloyed. The relationships are shown in Fig.4. According to colleted data, it is possible to extract $\mathrm{Na}$ and $\mathrm{K}$ from aqueous solution but with significantly lower adsorption capacity than for lithium chloride. It can be noted that the removal efficiency is maintained at 40 and $8 \%$ level for $\mathrm{KCl}$ and $\mathrm{NaCl}$, respectively. It could be concluded that LMTO had an unique ability for selective extraction of lithium ions from low salinity aqueous solutions. 


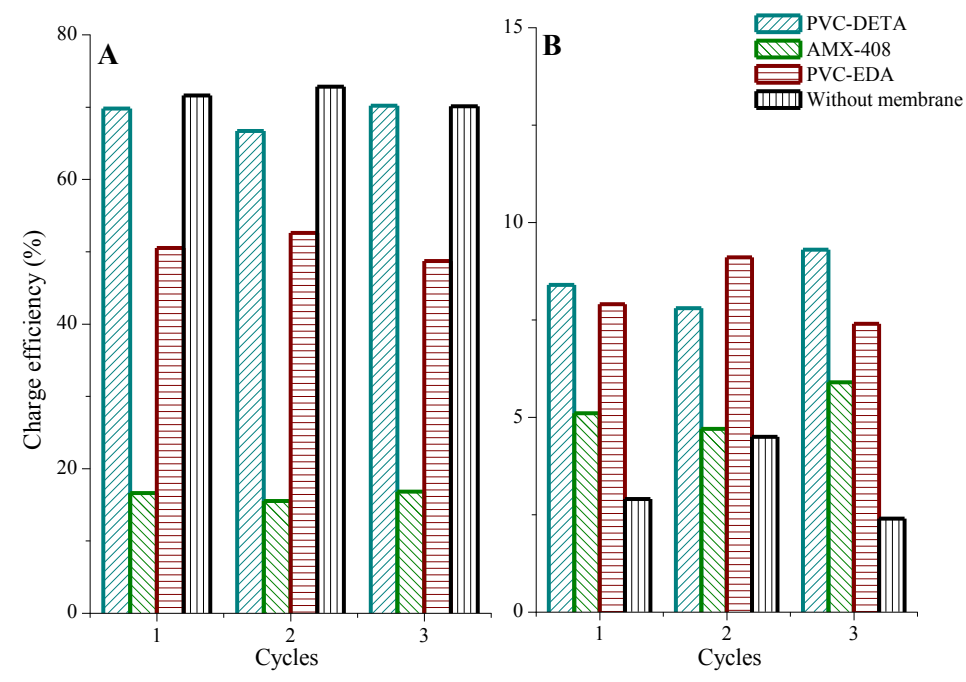

Fig.5. Date of charge efficiency vs. time of (A) adsorption and (B) desorption. Initial salt concentration was $10 \mathrm{mM}$, time of adsorption/desorption $10 \mathrm{~min}$, external voltage at $2 \mathrm{~V}$.

The next key metrics describing performances of any CDI system is its charge efficiency, which refers to ration between the amount of salt ions adsorption from bulk solution and the amount of electronic charge transferred between the electrodes. Fig.5. depicts the variation of the charge efficiency for evaluated configuration for charge and discharge steps. Observed differences with characteristic of charge efficiency are resulted from various kinetics of adsorption and desorption. The most stable course charge efficiency have PVCDETA and without membranes systems. During the discharge step, two important observations can be made after careful inspection of Fig. 5B. Firstly, charge efficiency was not more decreasing for system with higher salt removal degree. This effect could be explained by higher energetic requirements to get greater efficiency of desorption process. It indicated the work against concentration gradient. The second observation was that the charge efficiency of the stack with AMX-408 or without membrane slightly decreased and approached linear shape during the discharge step. We think that phenomenon was caused by minor degree of ions release from electrodes.

More representative metrics determined hybrid CDI system for lithium extraction are work that system has to devote for adsorb or desorb 1 gram of salt. The second metrics is ENAS that shows how much salt can be adsorb/desorb when 1 joules of energy passes the system. The energy requirements data for investigated stacks are collected in Tab.3.

Table 3. Work and ENAS for all membranes during adsorption and desorption process

\begin{tabular}{ccccc}
\hline & \multicolumn{2}{c}{ Adsorption } & \multicolumn{2}{c}{ Desorption } \\
\cline { 2 - 5 } & Work & ENAS & Work & ENAS \\
\cline { 2 - 5 } PVC-DETA & $W h / g$ & $m g / J$ & $W h / g$ & $m g / J$ \\
\hline AMX-408 & 0.08 & 3.62 & 0.64 & 0.44 \\
\hline PVC-EDA & 0.24 & 1.15 & 1.06 & 0.26 \\
\hline Without membrane & 0.10 & 2.61 & 0.68 & 0.41 \\
\hline
\end{tabular}

Based on the above results, stack with AMX-408 is characterized by the higher electrical work during charging step. It can be explained by membrane thickness (AMX-408 has an approximately $200 \mu \mathrm{m}$ thickness, two time larger than PVC membranes). However, during 
the discharge step, directly disadvantage of membrane-less system was observed. It could be the co-adsorption effect on counter electrode [7] that caused an increase of electrical work value. Moreover, systems with PVC-DETA was characterized by the most efficiency electrical work ratio, achieved 8 time lower value between charge/discharge steps. The ENAS metrics reach optimum values for that system.

\section{Conclusion}

The paper presents comparison different type of anion-exchange membranes used for selective extraction lithium ions from diluted aqueous solution in hybrid capacitive deionization or ion-pumping system. The studies pointed that combined system of LMTO selective adsorbent and PVC-DETA anion-exchange membrane allowed to obtain high adsorption capacity that value was $60 \%$ better for lithium chloride than for other alkaline chlorides. Moreover, the described hybrid system showed high energetic efficiency for lithium ions sorption/desorption processes. It reached the values of 0.08 and $0.64 \mathrm{Wh} / \mathrm{g}$, respectively. The developed system had higher capacity and lower energy consumption that configuration with industrial AMX-408 membrane.

\section{References}

1. H. Vikström, S. Davidsson, and M.Höök, App. Energy 110252 (2013)

2. P. Meshram, B.D. Pandey, and T.R. Mankhand, Hydrometallurgy 150192 (2014)

3. T. Ryu, D.-H. Lee, J.C. Ryu, J. Shin, K.-S. Chung, and K. H. Young, Hydrometallurgy 15178 (2015)

4. M. Pasta, C.D. Wessells, Y. Cui, and F. La Mantia, Nano Lett., 12839 (2012)

5. A. Siekierka, M. Bryjak, and J. Wolska, Desal. Wat. Treat. 64251 (2017)

6. M .Bryjak, A. Siekierka, J. Kujawski, K. Smolińska-Kempisty, and W. Kujawski, J. Memb. Separ. Tech 4110 (2015)

7. S. Porada, R. Zhao, A. Van der Wal, V. Presser, and P.M. Biesheuvel, Prog. Mater. Sci.58 1388 (2013)

8. A. Siekierka, J. Wolska, W. Kujawski, and M. Bryjak, Sep. Sci. Tech. (2017) [to be published]

9. Web page: http://www.astom-corp.jp/en/product/images/astom_hyo.pdf [available: 12.03.2017]

10. M.E. Suss, S. Porada, X. Sun, P.M. Biesheuvel, J. Yoon, and V. Presser, Energy Environ. Sci. 82296 (2015)

11. A. Hemmatifar, J.W. Palko, M. Stadermann, and J.G. Santiago, Water Res. 104303 (2016)

12. T. Kim, and J. Yoon, RSC Adv. 51456 (2015) 